Luísa Gouveia • Anabela Raymundo •

Ana Paula Batista · Isabel Sousa · José Empis

\title{
Chlorella vulgaris and Haematococcus pluvialis biomass as colouring and antioxidant in food emulsions
}

Received: 29 March 2005 / Revised: 1 July 2005 / Accepted: 5 July 2005 / Published online: 28 September 2005

(C) Springer-Verlag 2005

\begin{abstract}
The use of microalgal biomass, a natural ingredient, to colour oil-in-water pea protein stabilised emulsions was studied. Various levels of incorporation of Chlorella vulgaris green, Chlorella vulgaris orange (after carotenogenesis), and Haematococcus pluvialis (red, after carotenogenesis) were used, resulting in a wide range of appealing colours from green to orange and pink. The colour stability of the emulsions was evaluated, through the evolution of the $\mathrm{L}^{*} \mathrm{a}^{*} \mathrm{~b}^{*}$ parameters (CIELAB system) along 6 weeks. The primary and secondary oxidation products of the emulsions were also determined, and an enhanced resistance to oxidation was evidenced by emulsions containing microalgae. Therefore antioxidant functionality was another positive aspect of its use as an ingredient. Colour stability, a variety of attractive hues, and added resistance to oxidation ensure an adequate compromise of sensory and functional properties for these novel emulsions.
\end{abstract}

Keywords Microalgæ $\cdot$ Chorella vulgaris .

Haematococcus pluvialis · Emulsions · Colouring · Oxidation

L. Gouveia $(\bowtie)$

Instituto Nacional de Engenharia e Tecnologia Industrial -

INETI-DER- Unidade Biomassa, Estrada do Paço do Lumiar,

1649-038 Lisboa, Portugal

e-mail: luisa.gouveia@ineti.pt

Tel.: +351-21-7127210

Fax: +351-21-7127195

A. Raymundo - A. P. Batista

Instituto Piaget, Centro de Investigação em Eng Alimentar e

Biotecnologia, ISEIT de Almada, Quinta da Arreinela de Cima,

2800-305 Almada

I. Sousa

Secção de Ciência e Tecnologia dos Alimentos, Instituto

Superior de Agronomia, Universidade Técnica de Lisboa,

Tapada da Ajuda,

1349-017 Lisboa, Portugal

J. Empis

Centro de Eng Biológica e Química, IST, Av. Rovisco Pais, 1049-001 Lisboa, Portugal

\section{Introduction}

Modern food industry aims at an increase of cheaper, healthier and more convenient foods. The use of natural ingredients with functional activity is an attractive way to design new foods with an important impact on new markets niche.

Oil-in-water emulsions, such as mayonnaises and salad dressings, were traditionally stabilised by egg yolk lipoproteins. This protein can be fully replaced by vegetable protein isolates, as it was successfully tested $[1,2]$. The main advantages of this substitution results from the growing interest on low-cholesterol and animal-free food emulsions, low fat and easier to handle with an expected positive agricultural impact [1].

Besides health aspects, sensory characteristics are determinant for consumer acceptability, image, market size and commercial value. Colour, texture, shape and size are the important criteria as indicators of quality and freshness of food. In the past, synthetic pigments were thoroughly used to manipulate food colour. However, at present the priority is to replace artificial (synthetic) by natural colourings [3].

Microalgal biomass is a natural purveyor of biologically active compounds, such as carotenoids, phycobilins, fatty acids, polysaccharides, vitamins and sterols. Due to its content in natural pigments, especially of carotenoid nature, microalgal biomass can be used as colouring agent [4-7]. The harvesting time of microalgal biomass, cultivated in appropriate growth medium, determines a possible range of hues and colours, which can be monitored in terms of visible absorption spectrum [8]. It means that when the desired colour is "green", microalgal biomass harvesting should be very early; however, when the desired colour is "orange-red", carotenogenesis must progress over time and biomass harvesting must be performed on a latter stage.

In previous studies it has been observed that the incorporation of microalgal biomass in food emulsions does not destabilise its structural properties, and could even present a synergistic effect, increasing e.g. emulsions firmness; 
and reducing the oil content of the emulsion without disturbing their structural and sensory properties [9].

Lipid oxidation is a major cause for quality loss in food emulsions [10] due to the formation of undesirable volatile compounds, off-flavours (rancidity) and potentially toxic reaction products [11] which makes the emulsions less acceptable to consumers [12]. Besides colour, carotenoid pigments, under certain conditions, can retard lipid oxidation (antioxidants) in an array of lipid substrates [13, 14], which can be very advantageous when they are used as ingredients of high fat food products (e.g. mayonnaises). Microalgal biomass may be considered as multi-component antioxidant systems, which are generally more effective due to synergistic or additive interactions between the different antioxidant components $[15,16]$.

The mechanism that explains the performance of antioxidants in multiphase systems differs from that of inhibited lipid oxidation in bulk oils due to more complex interfacial phenomena that are expected to affect the antioxidant activity [10]. The portioning of antioxidant, between the lipid and aqueous phase, and consequently their efficacy, may be influenced by factors such as charge, interactions with the emulsifier and $\mathrm{pH}[10]$.

The aim of this work was to evaluate the ability of microalgal biomass to act as a pigment and as an antioxidant agent in food emulsions. Two microalgae were usedChlorella vulgaris (green and orange, after carotenogenesis) and Haematococcus pluvialis (red, carotenogenic) as colouring and antioxidant source for oil/water food emulsions stabilised by a pea protein interface. Hue and colour intensity (CIELAB system) of emulsions were determined as a function of pigment concentration. The antioxidant effect was evaluated over 6 weeks by determining primary and secondary oxidation products, respectively by peroxide value and $p$-anisidine value assessment.

\section{Materials and methods}

\section{Microalgæ}

Chlorella vulgaris (INETI 58) (Cv) and Haematococcus pluvialis (INETI 33) (Hp) were used in this study. The microalgæ were cultivated in appropriated growth medium [17] and after growing in airlift bioreactors, bubbling air, at $25^{\circ} \mathrm{C}$ temperature and at low light conditions $\left(150 \mu \mathrm{E} \mathrm{m}^{-2} \mathrm{~s}^{-1}\right)$, the Chlorella vulgaris (green) was recovered.

Carotenogenesis were performed by nitrogen starvation, $\mathrm{NaCl}$ addition (30\% for $\mathrm{Cv}$ (orange) [8] and 2\% for $\mathrm{Hp}$ (red) [18]), at high luminosity favoured by culture dilution (1000 $\mu \mathrm{E} \mathrm{m} \mathrm{m}^{-2} \mathrm{~s}^{-1}$ ). Microalgal biomass harvesting was produced without flocculation by simply removing agitation, concentration by centrifugation and freeze drying. Total pigment content was $0.2 \%$ w/w for $\mathrm{Cv}$ (green), $0.4 \% \mathrm{w} / \mathrm{w} \mathrm{Cv}$ (orange) and 1.2\% w/w for Hp (red) (dry basis), measured by acetone extraction method [8].
Emulsion preparation

Oil/water emulsions (mayonnaise like) with $3 \%(\mathrm{w} / \mathrm{w})$ pea protein isolate (Pisane HD, Cosura, Belgium) and containing $65 \%(\mathrm{w} / \mathrm{w})$ commercial oil were prepared with various different microalgal biomass incorporations: Chlorella vulgaris (green and orange) from $0.25 \%$ up to $2.00 \%$ (w/w); Haematococcus pluvialis from $0.05 \%$ up to $2.00 \%(\mathrm{w} / \mathrm{w})$ and a control, with no pigment added $(0 \%$ $\mathrm{w} / \mathrm{w})$. Protein isolate and freeze dried microalgae were dispersed in deionised water, under magnetic stirring (30 min) at room temperature. Emulsification was carried out using an Ultra Turrax T-25 (IKA, Germany), at constant mechanical energy (13000 rpm, $3 \mathrm{~min}$ ), as reported previously [19].

\section{Physical and chemical analysis}

\section{Colour}

The emulsion colours were measured instrumentally using a Minolta CR300 (Japan) colorimeter and the results were expressed in terms of $\mathrm{L}^{*}$ - lightness, $\mathrm{a}^{*}$ —redness and $b^{*}$-yellowness (CIELAB system). All measurements were conducted under the same light conditions, using a white standard $\left(\mathrm{L}^{*} 97.46, \mathrm{a}^{*}-0.02, \mathrm{~b}^{*} 1.72\right)$, at $20 \pm 1{ }^{\circ} \mathrm{C}$, replicated five times, at weekly intervals until week 6 th. The emulsions were kept refrigerated at $5{ }^{\circ} \mathrm{C}$.

\section{Oxidation products}

The emulsion's lipidic phase was extracted using the Bligh and Dyer method [20], with a binary mixture of non-polar solvents (chloroform and methanol).

The peroxide value, which indicated the initial occurrence of primary oxidation compounds, was determined on the 1st, 3rd and 6th weeks of the study according to [21]. This value shows the level of active oxygen (expressed in miliequivalents) and is related to the primary deterioration of the lipidic phase. The evaluation of secondary oxidation compounds, which measures the amount of peroxidised material already broken down to carbonyl compounds, was estimated by their $p$-anisidine values [22] in the first and last (6th) week of the study.

These determinations were performed in duplicate samples for emulsions containing $0.00,0.75$ and $1.25 \%$ microalgal biomass concentration.

\section{Statistical analysis}

All data are presented as mean \pm standard deviation and subjected to ANOVA-Post Hoc Comparisons-Scheffé test. Statistical significance was tested at a 0.05 probability level, performed by StatSoft STATISTICA program, version 5.0. 


\section{Results and discussion}

\section{Colour}

The use of microalgal biomass from Chlorella vulgaris (green and carotenogenic - orange) and Haematococcus pluvialis resulted in oil-in-water emulsion with a wide range of appealing colours (Fig. 1). Comparing the results obtained on the 1 st week with $0.25 \%$ biomass incorpora-

(a)

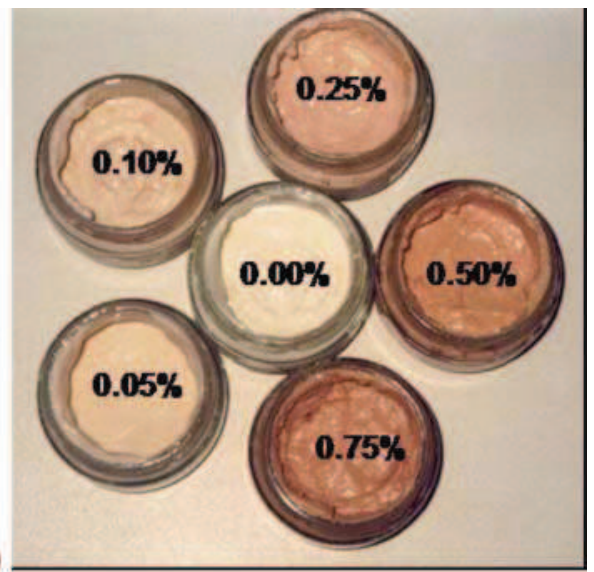

(b)

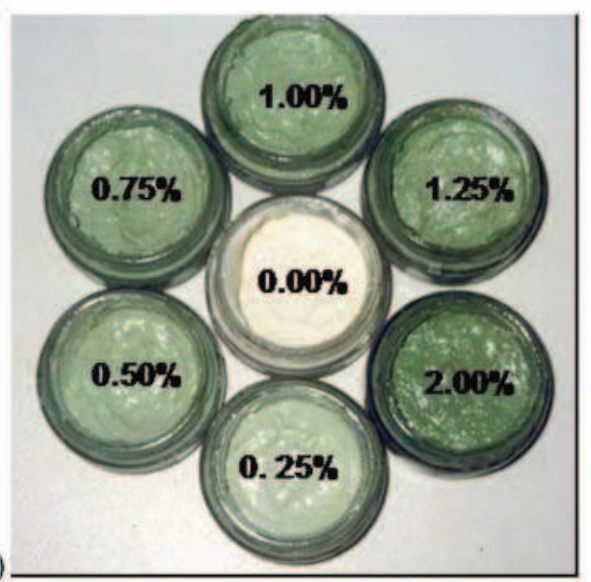

(c)

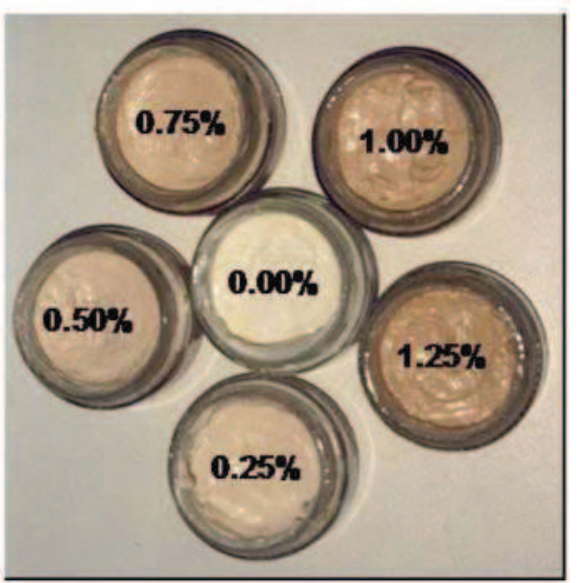

Fig. 1 Oil-in-water food emulsions coloured with different concentrations of a Haematococcus pluvialis, b Chlorella vulgaris green and $\mathbf{c}$ Chlorella vulgaris orange biomass tion, the emulsion with $\mathrm{Cv}$ green added presented green hue $\left(\mathrm{a}^{*}-9.29 ; \mathrm{b}^{*} 13.23\right)$; orange when $\mathrm{Cv}$ orange $\left(\mathrm{a}^{*} 2.15\right.$; $\left.\mathrm{b}^{*} 12.80\right)$ was used; pink with $\mathrm{Hp}\left(\mathrm{a}^{*} 7.10 ; \mathrm{b}^{*} 18.45\right)$.

Lightness parameter $L^{*}$ (Fig. 2) values were lower (darker) for the emulsions containing higher biomass concentrations, in all the microalgae studied. The emulsions with $\mathrm{Hp}$ incorporation levels above $0.25 \%$ presented a significant $(p<0.05)$ decrease on $\mathrm{L}^{*}$ values over time (particularly for $2 \%$ ), which should be related to a global colour degradation. Emulsions with Chlorella vulgaris were more stable, and a statistical evolution $(p<0.05)$ of $\mathrm{L}^{*}$ with time was only found for a few microalgal concentrations $(0.50 \% \mathrm{Cv}$ green and $0.25,0.75$, and $1.25 \% \mathrm{Cv}$ orange).
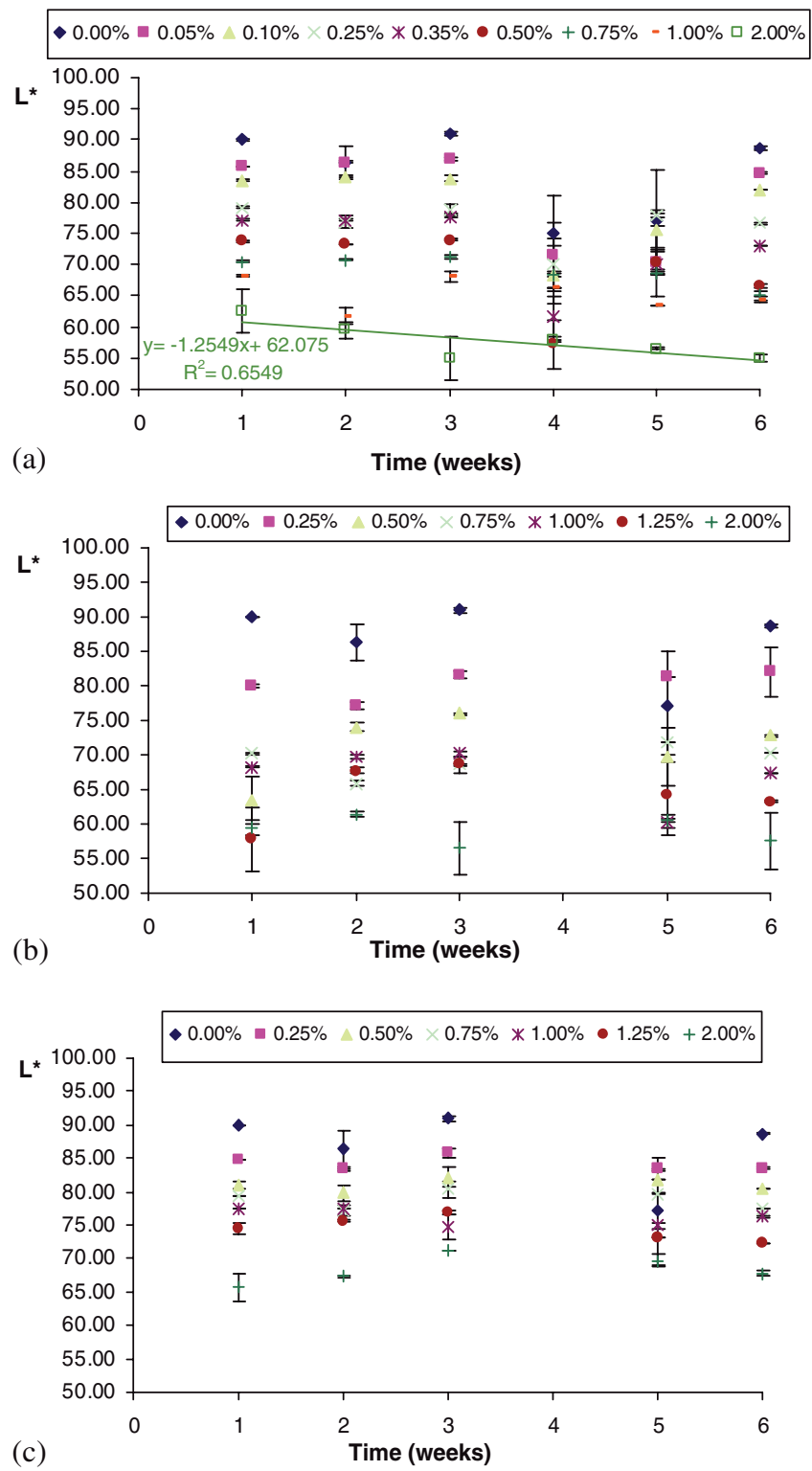

Fig. 2 Evolution of $\mathrm{L}^{*}$ values of $\mathrm{o} / \mathrm{w}$ emulsions coloured with different concentrations of a Haematococcus pluvialis, b Chlorella vulgaris green and c Chlorella vulgaris orange biomass, over time 
In relation to hue parameters (Fig. 3-5), $a^{*}$ and $b^{*}$ values increased with concentration for all microalgal biomass tested.

When $\mathrm{Cv}$ orange and $\mathrm{Hp}$ were used, increase of $\mathrm{a}^{*}$ and $\mathrm{b}^{*}$ values with concentration were observed, meaning that red and yellow hues were intensified, as expected. The Hp biomass shows higher hue values $\left(a^{*}\right.$ and $\left.b^{*}\right)$ when compared to $\mathrm{Cv}$ orange. This higher pigmentation capacity is only apparent, since at the same biomass concentration, the pigment content of $\mathrm{Hp}$ is three times higher than for $\mathrm{Cv}$ orange $-1.2 \%$ and $0.4 \%[8,18]$, respectively. When $\mathrm{Cv}$ green was used, the $\mathrm{a}^{*}$ parameter increased with biomass concentration, in absolute value, through negative, and $\mathrm{b}^{*}$ increased, meaning a predominance of green and yellow hues.

For $\mathrm{Hp}$ and $\mathrm{Cv}$ orange emulsions a significant $(p<0.05)$ increase of the $\mathrm{a}^{*}$ value over time was observed, revealing the existence of colour instability. These variations were more evident for concentrations higher than $0.35 \%$ of $\mathrm{Hp}$ and $1 \%$ of $\mathrm{Cv}$ orange, which correspond to an equivalent concentration of total pigments $(0.4 \% \mathrm{w} / \mathrm{w})$, being observed a linear relation between $\mathrm{a}^{*}$ parameter and time. These results suggest that using microalgal concentrations above these values, originates unstable colorations in $\mathrm{o} / \mathrm{w}$ emulsion.

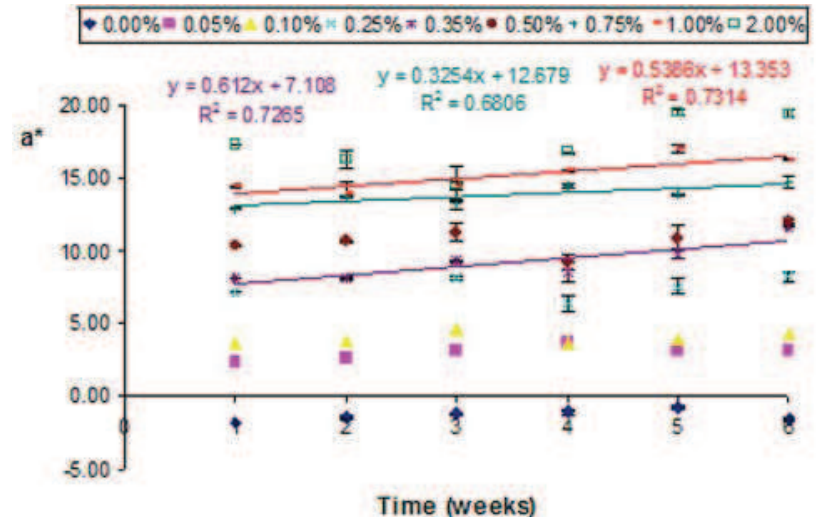

$-0.00 \%=0.05 \%=0.10 \%=0.25 \% \times 0.35 \% * 0.50 \%+0.75 \%=1.00 \% \square 2.00 \%$

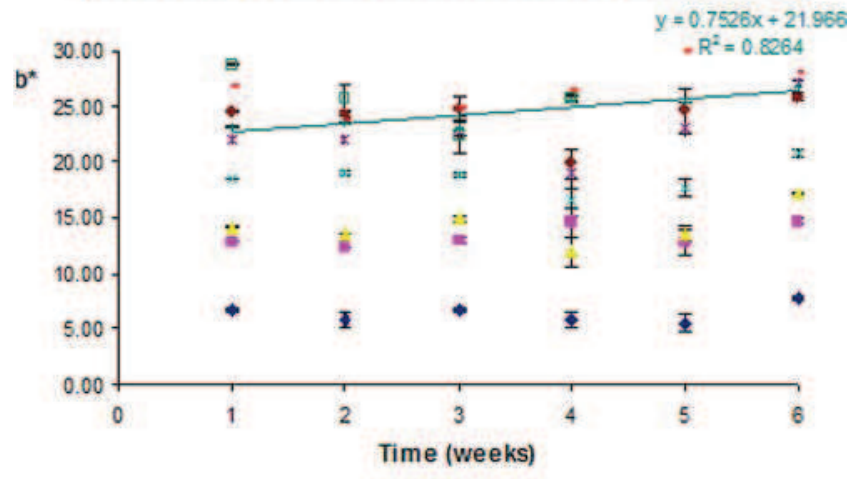

Fig. 3 Evolution of $\mathrm{a}^{*}$ and $\mathrm{b}^{*}$ values of $\mathrm{o} / \mathrm{w}$ emulsions coloured with different concentrations of Haematococcus pluvialis biomass, over time
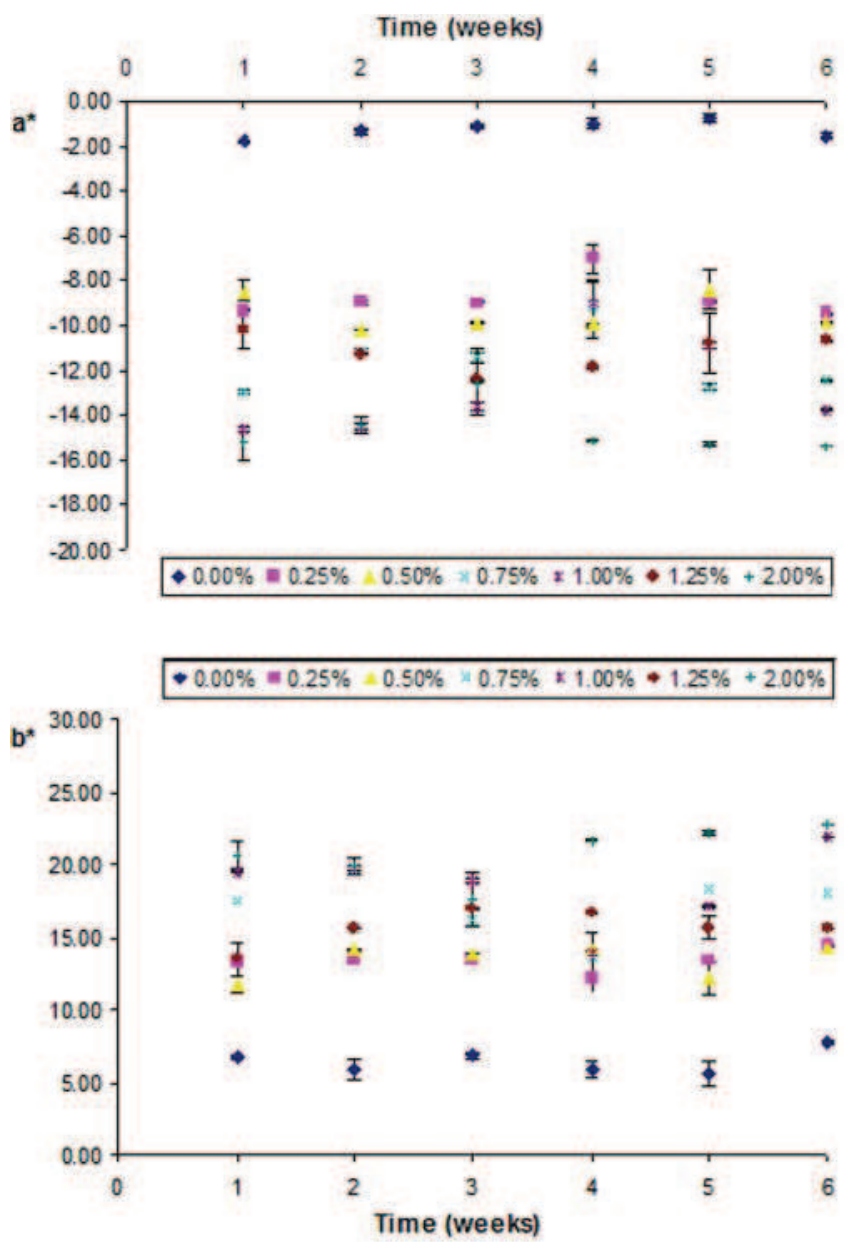

Fig. 4 Evolution of $\mathrm{a}^{*}$ and $\mathrm{b}^{*}$ values of o/w emulsions coloured with different concentrations of Chlorella vulgaris green biomass, over time

No significant differences $(p<0.05)$ with time were observed in $\mathrm{a}^{*}$ parameter when $\mathrm{Cv}$ green biomass was used as time went by, revealing a greater stability of these emulsions at all concentrations, for the period under study.

In relation to $b^{*}$ parameter it was observed a significant $(p<0.05)$ increase over time for all the emulsions studied, except $0.50 \% \mathrm{Hp}, 0.75 \% \mathrm{Cv}$ green and $1 \% \mathrm{Cv}$ orange emulsions which presented higher stability in relation to this colour parameter. For emulsions with concentrations above $1 \% \mathrm{Cv}$ orange or $\mathrm{Hp}$ it is observed a positive linear relation between $b^{*}$ parameter and time.

\section{Oxidation products}

In regard to primary oxidation compounds (peroxide value), the results from Fig. 6 show that addition of microalgal biomass to the emulsions, yielded smaller values of primary oxidation products. However, there is a considerable increase of oxidation products in the 3rd week for all the emulsions, namely for the control (without microalgal biomass addition). In the 6th week, primary oxidation compounds decreased (Fig. 6), probably due to 

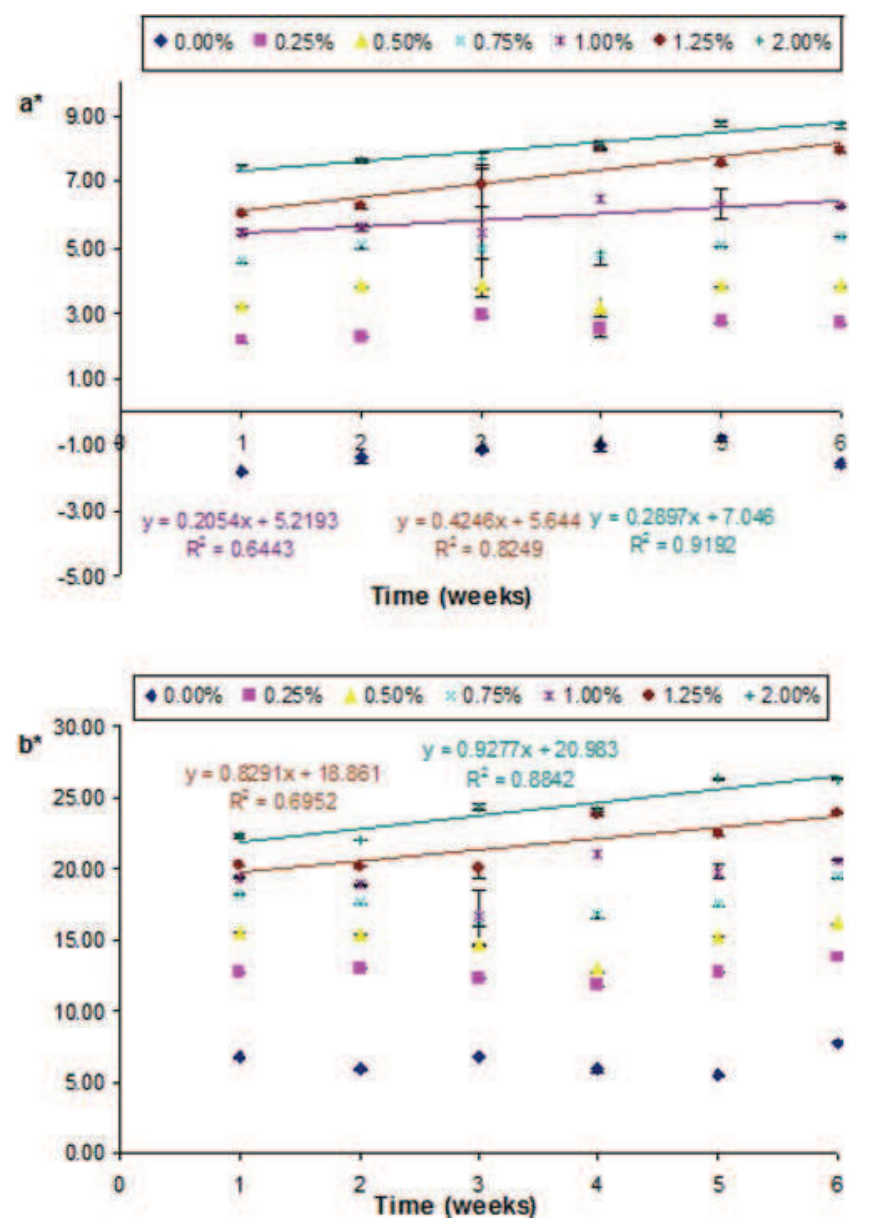

Fig. 5 Evolution of $\mathrm{a}^{*}$ and $\mathrm{b}^{*}$ values of o/w emulsions coloured with different concentrations of Chlorella vulgaris orange biomass, over time

the conversion into secondary oxidation products. This was confirmed by the results from Table 1 , in which an increase of secondary oxidation compounds from the 1 st to the 6th week, assessed by the $p$-anisidine value, is evident.

The incorporation of $\mathrm{Hp}$ and $\mathrm{Cv}$ green microalgal biomass provided a higher oxidation stability over time, in comparison with $\mathrm{Cv}$ orange (Table 1). Nevertheless, $\mathrm{Cv}$ orange revealed lower peroxide value, suggesting a rapid transformation of the primary oxidation compounds into secondary ones. For $0.75 \%$ microalgal biomass concentration $\mathrm{Cv}$ orange emulsions presented lower peroxide values than $\mathrm{Hp}$, while for higher incorporation levels $(1.25 \%)$ the opposite situation occurs. Considering that astaxanthin

Table 1 Secondary oxidation products concentration $-p$-anisidin value, from oil-in-water emulsions, incorporated with Haematococcus pluvialis, Chlorella vulgaris green and Chlorella vulgaris orange biomass

\begin{tabular}{llllll}
\hline Biomass concentration $(\% \mathrm{w} / \mathrm{w})$ & \multicolumn{2}{l}{1 st week } & & \multicolumn{2}{l}{ 6th week } \\
\cline { 2 - 3 } \cline { 6 - 7 } & 0.75 & 1.25 & & 0.75 & 1.25 \\
\hline Haematococcus pluvialis & 1.04 & 0.32 & & 4.05 & 4.84 \\
Chlorella vulgaris green & 0.97 & 0.95 & & 4.59 & 2.41 \\
Chlorella vulgaris orange & 1.18 & 1.18 & & 5.73 & 6.23 \\
\hline
\end{tabular}
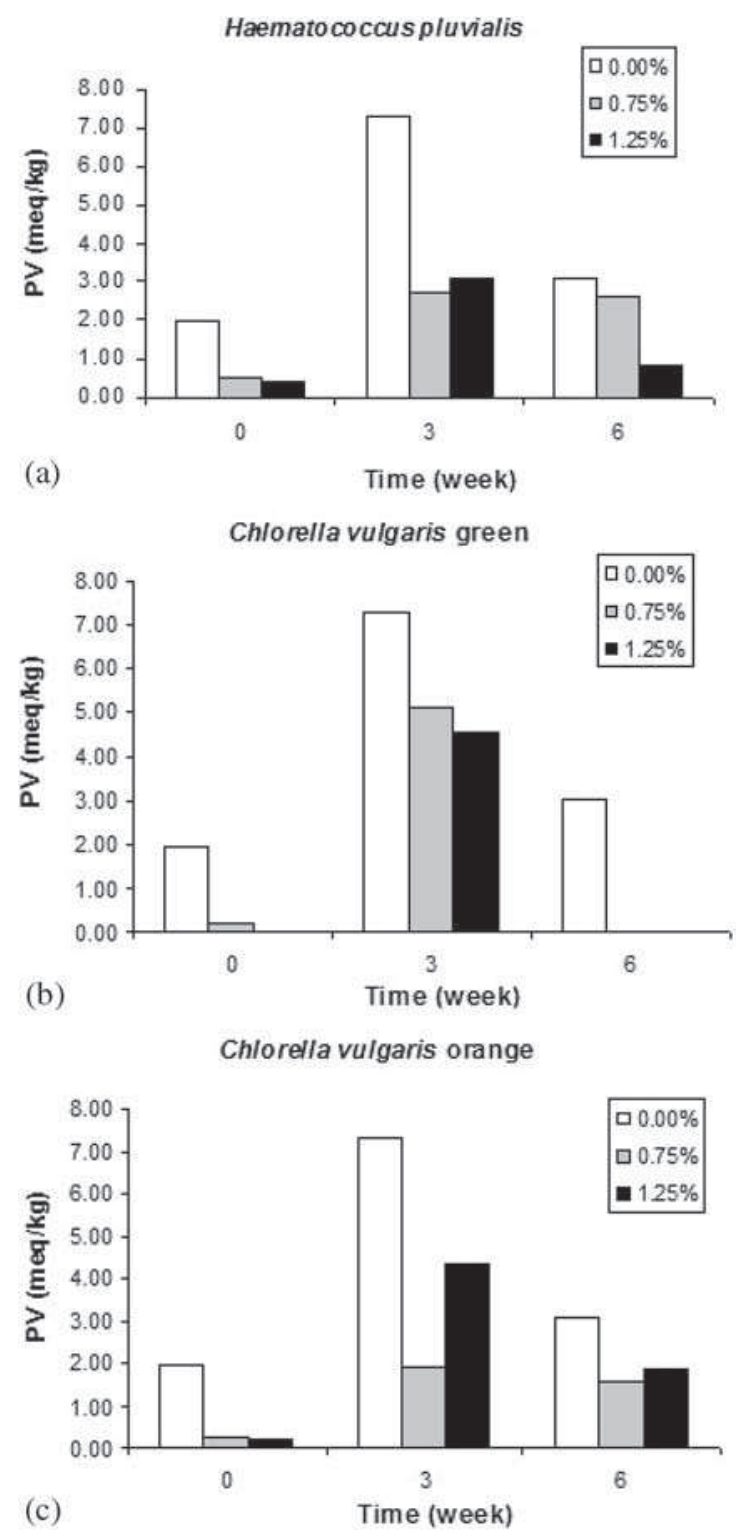

Fig. 6 Primary oxidation products concentration-peroxide value (PV), from oil-in-water emulsions, incorporated with a Haematococcus pluvialis, b Chlorella vulgaris green and $\mathbf{c}$ Chlorella vulgaris orange biomass

is the predominant pigment in Hp [18], canthaxanthin the dominant of $\mathrm{Cv}$ (orange) [8], and lutein the main of $\mathrm{Cv}$ (green) [8], could explain the differences found between these microalgae, in terms of retarding oxidation in oil-in-water emulsions. The higher oxidation stability of astaxanthin was already been reported; the antioxidant effectiveness of carotenoids increased as the number of the conjugated double bounds of carotenoids increased [23].

\section{Conclusions}

The growing trends toward improving the quality, variability and convenience of processed foods, removing or reducing the amounts of constituents associated with 
humans health concerns, such as fat, salt and cholesterol, can lead to the interest of preparing oil-in-water vegetable protein emulsions, such as mayonnaises coloured with microalgal biomass, which is a functional ingredient, due to its antioxidant activity.

Chlorella vulgaris (green and orange, after carotenogenesis) and Haematococcus pluvialis (red, after carotenogenesis), microalgal natural products, showed to be appropriate purveyor of pigments in oil/water vegetable food emulsions, proved to impart a stable and appealing colour to food emulsions improving the product ranges, with additional advantages in terms of antioxidant effects. It has also been observed in previous studies that the addition of these microalgae presents a positive effect on the emulsion's stability and rheological characteristics, especially for $\mathrm{Cv}$ green due to its higher protein content [9].

When the desired colour is "green", Chlorella vulgaris green biomass revealed to be a good mayonnaise ingredient, both in terms of sensory characteristics, namely colour, with good colour stability over time, but also showing good antioxidant performance.

When the interest is "orange-red" mayonnaise colour, in spite of similar behaviour of colour parameters for both microalgal biomass (Haematococcus pluvialis and Chlorella vulgaris orange), the first one seems to have a better performance as an antioxidant (lower primary and secondary oxidation compounds), mainly because the pigment concentration is larger.

From the three microalgae studied, $\mathrm{Cv}$ green showed higher colouring stability for the whole range of concentrations studied. The use of this microalga is related with lower costs for the global process, since full blown carotenogenesis is not necessary and the algae can be harvested during the log phase of its growth, quickly freeing the system for another batch.

Acknowledgements The authors thank Eng. Manuel Resendes and Eng. Ana Miranda for technical support; Graça Conceição for microalgal biomass production; and COSUCRA (Belgium) for providing pea protein isolate samples.

\section{References}

1. Raymundo A, Franco J, Gallegos C, Empis J, Sousa I (1998) Nahrung 42:220-224

2. Raymundo A, Franco J, Empis J, Sousa I (2002) J Am Oil Chemists Society 79:783-790

3. Britton G (1999) In: Mosquera MI, Galán MJ, Mendéz DH (eds) Pigments in Food Technology. In: Proceedings of 1st International Congress Pigments in Food Technology, Sevilla, Spain

4. Gouveia L, Veloso V, Reis A, Fernandes HL, Empis J, Novais JM (1996) J Sci Food Agric 70:167-172

5. Gouveia L, Gomes E, Empis J (1996) Z Lebensm Unters Forsch 202:75-79

6. Gouveia L, Choubert G, Gomes E, Pereira N, Santinha J, Empis J (2002) Aquac Research 33:987-993

7. Gouveia L, Rema P, Pereira O, Empis J (2003a) Aquac Nutrition 9(3):123-129

8. Gouveia L, Veloso V, Reis A, Fernandes HL, Empis J, Novais JM (1996) Biores Technol 57:157-163

9. Raymundo A, Gouveia L, Batista AP, Empis J, Sousa I (2005) Food Research International (in press)

10. McClements D, Decker EA (2000) J Food Sci 65(8):12701282

11. Halliwell B, Murcia MA, Chirico S, Aruoma OI (1995) Crit Rev Food Sci Nutr 35:7-20

12. Min D, Ticknor D (1982) J Am Oil Chem Soc 59(5):226228

13. Bast A, Haanen GR, Van den Berg H (1998) Int J Vitam Nutrit Res 68:399-403

14. Nenadis N, Zafiropoulou I, Tsimidou M. (2003) Food Chem 82:403-407

15. Decker EA (1998) Trends Food Sci Technol 9:241-248

16. Kiokias S, Gordon MH (2003) Food Chem 83:523-529

17. Vonshak A (1986) In: Richmond A (ed) CRC handbook of microalgal mass culture. CRC Press, Boca Raton, USA, pp 117-143

18. Gouveia L, Empis J (2003b) Innov Food Sci Emerg Technol 4:227-233

19. Franco JM, Raymundo A, Sousa I, Gallegos C (1998) J Agric Food Chem 46:3109-3115

20. Bligh EG, Dyer WJ (1959) Can J Biochem Physiol 37:911917

21. NP-904 (1972) Portuguese Norm. Edible fats and oils. Peroxide value determination

22. NP-1819 (1984) Portuguese Norm. Edible fats and oils. $p$-anisidine value determination

23. Yen WJ, Chen BH (1995) Food Chem 53:417-425 